\title{
МОНИТОРИНГ ГОСУДАРСТВЕННЫХ ЗАКУПОК КАК ЭЛЕМЕНТА СИСТЕМЫ ЭКОНОМИЧЕСКОЙ БЕЗОПАСНОСТИ РЕГИОНА: ПУТИ ЕГО СОВЕРШЕНСТВОВАНИЯ
}

\author{
(C) 2021 Кравченко Валентина Витальевна \\ ассистент, Высшая инженерно-экономическая школа \\ Санкт-Петербургский политехнический университет Петра Великого, Россия, Санкт-Петербург \\ E-mail:kravchenko_vv@spbstu.ru
}

\section{(C) 2021 Кудрявцева Татьяна Юрьевна}

доктор экономических наук, профессор, доцент, Высшая инженерно-экономическая школа Санкт-Петербургский политехнический университет Петра Великого, Россия, Санкт-Петербург

Система экономической безопасности региона имеет сложную структуру и состоит из множества элементов, экономическая безопасность каждого из которых важна для системы в целом. В качестве такого системообразующего элемента выступают государственные закупки, посредством которых обеспечиваются общественные блага, на реализацию которых расходуется до $10 \%$ ВВП страны. Именно государственные закупки выступают мощным механизмом со стороны государства, обеспечивающим и поддерживающим должный уровень конкуренции. В это же время государство посредствам федерального органа исполнительной власти по регулированию контрактной системы в сфере закупок осуществляет мониторинг, сбор, обобщение, систематизацию и оценку информации. Однако существующий метод мониторинга государственных закупок не позволяет заблаговременно распознать угрозы системы экономической безопасности региона, выраженные в различных способах преступлений в сфере государственных закупок. В связи с этим было предложено внедрить методику, основанную на взаимосвязи уровня конкуренции и экономии, для усовершенствования процесса мониторинга государственных закупок со стороны Министерства Финансов РФ.

Ключевые слова: государственные закупки, экономическая безопасность, экономическая безопасность региона, мониторинг, Министерство Финансов

\section{Введение}

Система экономической безопасности региона состоит из взаимосвязанных между собой элементов региональной экономической системы, через которые проходят различные формы государственных расходов, такие как государственные субсидии, прямое бюджетное финансирование государственных предприятий и учреждений, закупки товаров, услуг и работ для государственных нужд (государственные заказы) и денежные выплаты лицам, охваченным программами социальной помощи и страхования.

Доля государственных закупок в общем объеме ВВП Российской Федерации ежегодно увеличивается. В 2014 цена контрактов составляла 5,5 трлн. рублей, что составляло $6,3 \%$ от ВВП. В 2020 году доля государственных закупок увеличилась до $10 \%$, что соответствует 8,9 трлн. рублей. Это процесс, посредством которого центральные, региональные и местные органы власти, а также государственные органы, органы и агентства, регулируемые публичным правом и нормативными актами, приобретают и вводят в эксплуатацию услуги, общественные работы и сопутствующие товары и материалы.

С помощью государственных закупок правительство использует свою покупательную способность как инструмент для достижения определенных социальных и политических целей [17]. Государственные закупки по своей роли в экономике выступают связующим механизмом между государством и общественными благами, которые являются основным результатом деятельности в общественном секторе [16]. С помощью государственных закупок товаров, работ и услуг осуществляются общественные расходы для удовлетворения потребностей общества [16]. Иными словами, при рациональном осуществлении государственных закупок на приобретение нужных и высококачественных товаров, работ и услуг, общество, являющееся основным потребителем данных благ, считается удовлетворенным, система развивается в соответствии 
со всеми законами.

Уместно утверждать, что при неблагоприятных условиях институциональной подсистемы для функционирования заимствованного инструмента государственного вмешательства в экономику и как следствие неправильном использовании в финансово-бюджетной подсистеме механизма государственных закупок за счет предоставления некачественных товаров, работ и услуг из системы производства товаров и услуг, или нарушения правил рыночной конкуренции страдают конечные потребители данных благ, то есть общество, потребительская и социальная подсистема $[1,14]$. Это запускает процесс возникновения отклонений во всех элементах системы экономической безопасности региона [2, 4]. Кроме того, возникает угроза неравного условия для развития конкуренции на рынке, дополнительного расходования бюджетных средств, а, следовательно, продолжительный ряд воздействий на систему экономической безопасности, несущих прямые и косвенные угрозы для ее стабильного развития.

Комплексное управление сложной и развивающейся системой возможно на основе сбора и анализа непрерывного потока информации о ее состоянии, а также закономерностях всей совокупности процессов, протекающих в ней [7]. «Для соблюдения обеспечения принципов контрактной системы, о которых сказано в статье 6 Федерального закона № 44, а именно о принципах открытости, прозрачности информации о контрактной системе в сфере закупок, обеспечения конкуренции, профессионализма заказчиков, стимулирования инноваций, единства контрактной системы в сфере закупок, ответственности за результативность обеспечения государственных и муниципальных нужд, эффективности осуществления закупок, осуществляется контроль, мониторинг и аудит со стороны органов государственной власти» [5]. В данной статье более детально будет рассмотрен процесс мониторинга государственных закупок.

\section{Обзор литературы}

Мониторинг закупок представляет систему наблюдений в сфере закупок, осуществляемую на постоянной основе посредством сбора, обобщения, систематизации и оценки информации об осуществлении закупок. Мониторинг осуществляется на основе информации, содержащейся в единой информационной системе. Мониторинг осуществляет Министерством Фи- нансов Российской Федерации.

Сводный аналитический отчет по итогам календарного года является результатом мониторинга закупок товаров, работ, услуг для обеспечения государственных и муниципальных нужд. Он предоставляется в Правительство РФ до 30 апреля следующего за отчетным годом. Аналитический отчет состоит из систематизированной информации о планировании и осуществлении закупок, результатов контроля в сфере закупок, об оценке эффективности, о совершенствовании законодательства в сферах закупок. Важно отметить, что согласно методике мониторинга государственных закупок, результативность закупок - это доля заключенных и исполненных контрактов, а также экономия по результатам проведения процедуры закупки.

В соответствии с актами высших исполнительных органов государственной власти субъектов Российской Федерации, мониторинг закупок для обеспечения нужд субъектов Российской Федерации может осуществляться органами исполнительной власти субъектов Российской Федерации по регулированию контрактной системы в сфере закупок, органами местного самоуправления.

Таким образом, мониторинг государственных закупок - это сложная информационноаналитическая система непрерывного сбора, общения, систематизации и оценки информации из Единой информационной системы в течение отчетного периода, создаваемая и регулируемая Министерством Финансов РФ или органами исполнительной власти субъектов РФ по регулированию контрактной системы в сфере закупок с целью оценки степени достижения целей осуществления закупок, обоснованности закупок и совершенствования законодательства и иных нормативных правовых актов о контрактной системе в сфере закупок.

В контексте экономической безопасности инструментарий мониторинга может зависеть от выбора классификационного признака, по которому он проводится. Кроме того, на основании предложенных критериев отдельно выделяют пять методов проведения мониторинга, в том числе анализ и прогнозирование:

1. «Метод наблюдения основных макроэкономических показателей и сравнения их с пороговыми значениями;

2. Метод отслеживания темпов экономического роста по динамике изменений основных 
макроэкономических показателей;

3. Метод ранжирования территорий, использующий экспертные оценки;

4. Методы многомерного статистического анализа;

5. Оценка последствий угроз безопасности через количественное определение ущерба» [15].

Самым популярными методами мониторинга экономической безопасности региона среди отечественных исследователей является индексный подход [10], междисциплинарный [9] и индикативный подход $[8,11]$, которые по своей сущности представляют аналогичный алгоритм действий.

По мнению автора, современные методы мониторинга, в том числе мониторинг государственных закупок, позволяют определить зоны выявленных угроз, то есть акцентировать свое внимание на определенных сферах, но не дают взаимосвязанной картины появления угроз экономической безопасности. Для полноценного мониторинга, а, следовательно, и предотвращения распространения угроз экономической безопасности региона необходимо знать влияние сфер друг на друга, что может быть достигнуто с помощью комплексного подхода, основанного на совокупности методов, в том числе методе регрессионного анализа. Регрессионный анализ предназначен для исследования зависимости исследуемой переменной от различных факторов и отображения их взаимосвязи в форме регрессионной модели [12].

Метод исследования

Автором был разработан метод оценки угроз системы экономической безопасности со стороны государственных закупок [6, 18]. Было определено, что наибольшие риски для системы связаны со связью между конкуренцией и экономией бюджета. Было предложено разделить регионы на четыре группы: неэффективные государственные закупки (группа 1), эффективные государственные закупки (группа 4) и государственные закупки, угрожающие системе экономической безопасности региона, то есть высокая конкуренция при экономии ниже среднего уровня по стране (группа 3) и низкая кон- куренция при уровне экономии выше среднего (группа 2).

Важность этого метода заключается в том, что внедрение его в процесс мониторинга государственных закупок позволит разработать индивидуальные инструменты регулирования элемента экономической безопасности, что позитивно отразиться на всей системе экономической безопасности региона.

\section{Результаты}

Министерство Финансов РФ публикует на своем официальном сайте аналитический отчет по результатам осуществления мониторинга закупок, товаров, услуг для обеспечения государственных и муниципальных нужд в соответствии федеральным законом от 5 апреля 2013 г. № 44-Ф3. Отчеты предоставляются ежеквартально и один годовой. Государственные закупки рассматриваются с точки зрения уровня осуществления закупок: федеральный, уровень субъекта и муниципальный уровни. В четвертой части отчета Минфина есть параграф, посвящённый информации о количестве поданных заявок, в пятой - общая экономия по итогам осуществления закупок. В случае уровня конкуренции выделяются отдельно лидеры по всем уровням осуществления закупок, по экономии - объем закупок с падением цены более чем на $25 \%$.

Предлагается использовать разработанную методику, выраженную в нескольких аспектах (Рисунок 1).

Во-первых, общую конкуренцию и общую экономию есть смысл демонстрировать совместно, так как они являются взаимосвязанными показателями осуществления государственных закупок, что было доказано. Во-вторых, рекомендуется дополнительно группировать информацию в соответствии с таблицей 1: то есть указывать объем закупок, проведенных с уровнем экономии и конкуренции ниже среднего по России; с высокой конкуренцией, но экономией ниже среднего; с низкой конкуренцией и экономией выше среднего; с экономией и конкуренцией выше средних значений по России, - с указанием уровня проведения государ-

Таблица 1. Распределение регионов по группам

\begin{tabular}{|c|c|c|}
\hline \multirow{2}{*}{$\begin{array}{l}\text { Количество участников на одну закупку } \\
\text { в регионе }\end{array}$} & \multicolumn{2}{|c|}{ Снижение первоначальной цены на одну закупку в регионе } \\
\hline & $\begin{array}{c}\text { Уровень ниже среднего } \\
\text { значения по России }\end{array}$ & $\begin{array}{c}\text { Уровень выше среднего } \\
\text { значения по России }\end{array}$ \\
\hline Уровень выше среднего значения по России & 3 & 4 \\
\hline Уровень ниже среднего значения по России & 1 & 2 \\
\hline
\end{tabular}




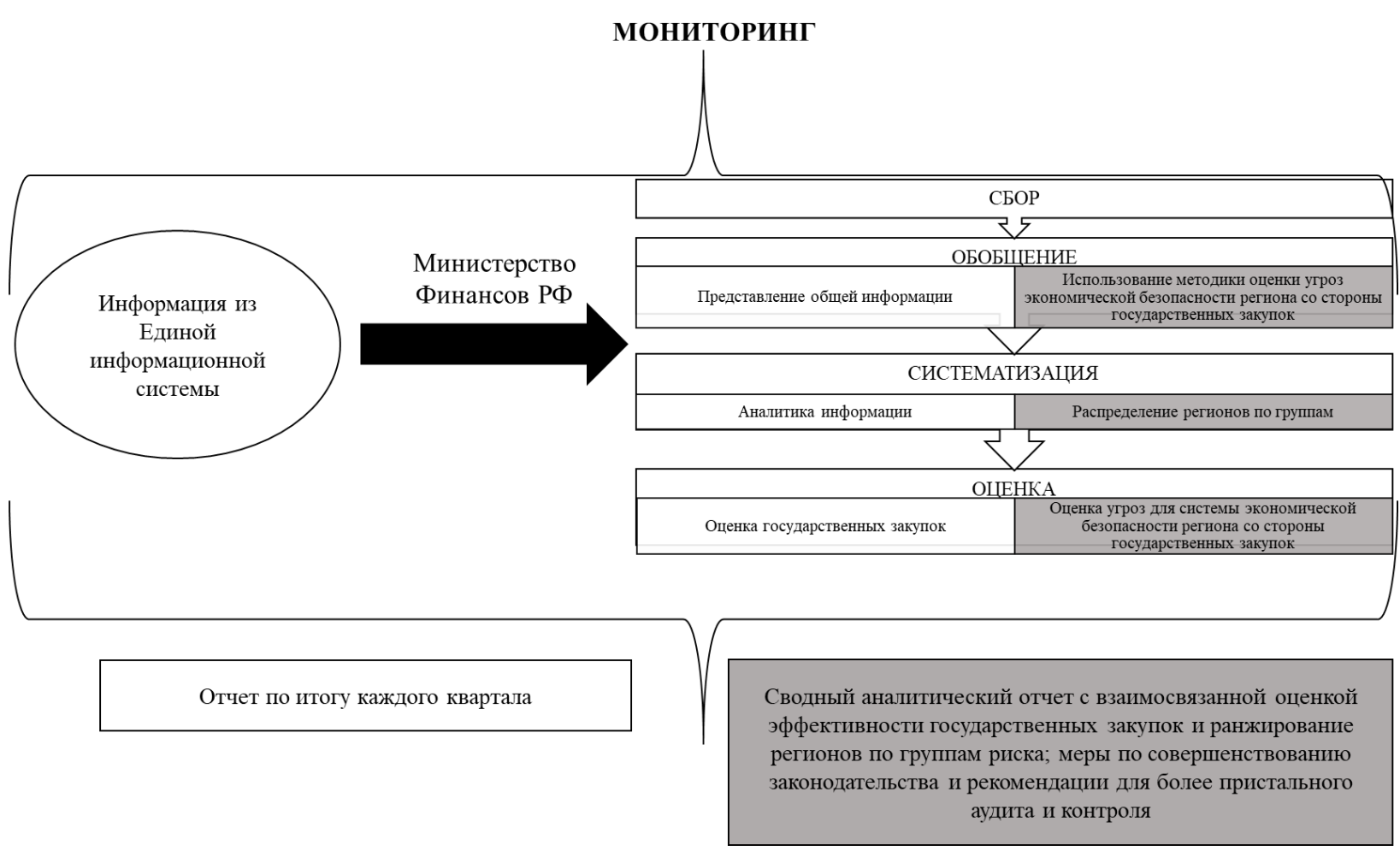

Рисунок 1. Усовершенствованный процесс мониторинга государственных закупок [составлено автором]

ственных закупок и последующей детализации по регионам при необходимости. Это позволит более полно представлять информацию о государственных закупках для заинтересованных в улучшения данной системы лиц.

\section{Bыводы}

В результате здоровой конкуренции производители товаров и услуг стараются делать акцент на повышении удовлетворения потребностей общества [6]. Отсутствие конкуренции при осуществлении государственных закупок влечет монополизацию рынка, что приводит к росту затрат производителя и к снижению удовлетворённости общества от получаемых благ [3]. Иными словами, отсутствует окупаемость затрат результатами и соответствие принятым критериям оценки. Такие последствия могут привести к неустойчивому процессу развития экономики и социально-экономической стабильности общества, что напрямую несет угрозу для системы экономической безопасности не только регионов, но и страны в целом.

\section{Библиографический список}

1. Дроздов В.Ю. Х. Н. Б. СОЦИАЛЬНО-ЭКОНОМИЧЕСКАЯ БЕЗОПАСНОСТЬ ГОСУДАРСТВА: ЧЕРЕЗ ПРИЗМУ СУБЪЕКТИВНЫХ ПРИЗНАКОВ ПРЕСТУПЛЕНИЙ, СОВЕРШАЕМЫХ В СФЕРЕ ГОСУДАРСТВЕННЫХ ЗАКУПОК // ГОСУДАРСТВО, ГРАЖДАНСКОЕ ОБЩЕСТВО И СТАБИЛЬНОСТЬ. 2019. (1). С. 100-112.

2. Дронов Р. В., Безденежных Т. В. Коррупция как угроза финансовой безопасности России 2016.С. 365-370.

3. Илий С.К., Аристархов А.Л. Игонина Н.А. И др БОРЬБА С КОРРУПЦИОННЫМИ ПРАВОНАРУШЕНИЯМИ В СФЕРЕ ИСПОЛЬЗОВАНИЯ ГОСУДАРСТВЕННОГО ИМУЩЕСТВА И ГОСУДАРСТВЕННЫХ ЗАКУПОК СРЕДСТВАМИ ПРОКУРОРСКОГО НАДЗОРА // 2014. С. 120.

4. Кириленко В. П., Дронов Р. В. Коррупция как угроза безопасности России и нарушение деловой этики государственных служащих // Политика и правовое государство. 2016. (8). С. 8-14.

5. Кравченко В.В. Контроль, мониторинг и аудит в сфере государственных закупок // Российский экономический интернет-журнал. 2019. (4). С. 82.

6. Кравченко В. В., КУдрявцева Т. Ю. ОЦЕНКА ЭКОНОМИЧЕСКОЙ БЕЗОПАСНОСТИ РЕГИОНА НА ОСНОВЕ ЭФФЕКТИВНОСТИ ГОСУДАРСТВЕННЫХ ЗАКУПОК // Национальные интересы: приоритеты и безопасность. 2020. (16). С. 2086-2102. 
7. Масленникова Н. Ю., Слинкова О. К. ПОНЯТИЕ И СУЩНОСТЬ МОНИТОРИНГА С ПОЗИЦИИ СИСТЕМНОГО ПОДХОДА // Science time. С. 555-558.

8. Новикова И. В., Красников Н. И. Индикаторы экономической безопасности региона // Экономика. 2019. (11). C. $132-138$.

9. Сенчагов В. К., Иванов Е. А. СТРУКТУРА МЕХАНИЗМА СОВРЕМЕННОГО МОНИТОРИНГА ЭКОНОМИЧЕСКОЙ БЕЗОПАСНОСТИ РОССИИ Москва. 2015.

10. Сенчагов В. К., Митяков С. Н. Использование индексного метода для оценки уровня экономической безопасности // Вестник Академии экономической безопасности МВД России. 2011. (5). С. 41-50.

11. СУшкова И. А. МОНИТОРИНГ КАК ОСНОВНОЙ ИНСТРУМЕНТ ОПРЕДЕЛЕНИЯ УРОВНЯ ЭКОНОМИЧЕСКОЙ БЕЗОПАСНОСТИ РЕГИОНА // Journal of Chemical Information and Modeling. 2019. № 9 (53). С. 1689-1699.

12. Схведиани А.Е. Основные предпосылки классической линейной регрессии и последствия их нарушений // Инновации и инвестиции. 2020. (8).

13. Федорова Л. П., БарсУКова М.В. ФОРМИРОВАНИЕ И РЕАЛИЗАЦИЯ МОДЕЛИ ЭКОНОМИЧЕСКОЙ БЕЗОПАСНОСТИ РЕГИОНА // ЭКОНОМИЧЕСКИЕ НАУКИ. 2019. № February 2004 (119).

14. Феофилова Т. Ю. . Система экономической безопасности региона: понятие и структура // Журнал правовых и экономический исследований. 2013. (4). С. 184-188.

15. Чичканов В.П., Беляевская-Плотник Л. А. АНАЛИЗ ПОДХОДОВ К ОЦЕНКЕ РЕГИОНАЛЬНЫХ ПРОЦЕССОВ ФОРМИРОВАНИЯ СОЦИАЛЬНО-ЭКОНОМИЧЕСКОЙ БЕЗОПАСНОСТИ // ЭКОНОМИКа регИона. 2016. № 3 (3). С. 654-669.

16. Якобсон Л. И. Государственный Сектор Экономики: Экономическая Теория И Политика: Учебник Для Вузов / Л.И. Якобсон, 2000.

17. Qiao Y., Thai K. V., Cummings G. State and local procurement preferences: A survey // Journal of Public Procurement. 2009. № 3/4 (9). C. 371-410.

18. Kravchenko V., Kudryavtseva T., Kuporov Y. A method for assessing threats to the economic security of a region: A case study of public procurement in Russia // Risks. 2021. № 1 (9). C. 1-10. 